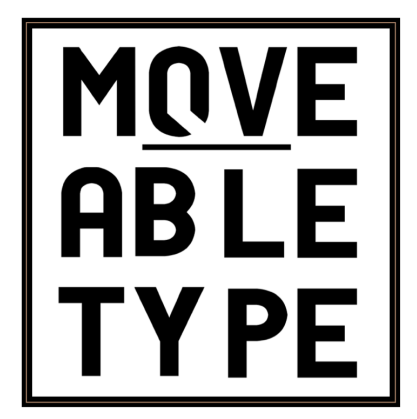

Review: Notes on a Scandal

Author[s]: Eileen Pollard

Source: MoveableType, Vol.3, 'From Memory to Event (2007)

DOI: $10.14324 / 111.1755-4527.030$

MoveableType is a Graduate, Peer-Reviewed Journal based in the Department of English at UCL.

(C) 2007 Eileen Pollard. This is an Open Access article distributed under the terms of the Creative Commons Attribution License (CC-BY) 4.0https://creativecommons.org/licenses/by/4.0/, which permits unrestricted use, distribution, and reproduction in any medium, provided the original author and source are credited.

\title{
UCLPRESS
}




\section{Notes on a Scandal}

by Eileen Pollard

Novel by Zoë Heller

London: Penguin, 1997

Film Dir. Richard Eyre

Twentieth Century Fox, 2006

R ichard Eyre's dark film lacks the subtle intricacies of self-delusion Wintegral to Zoë Heller's novel. Barbara Covett might be, as Eyre states, 'a gloriously unreliable narrator', ${ }^{1}$ but as such she displays all the psychology of absolute self-deceit:

There are certain people in whom you can detect the seeds of madness - seeds that have remained dormant only because the people in question have lived relatively comfortable middle-class lives. They function perfectly well in the world, but you can imagine, given a nasty parent, or a prolonged bout of unemployment, how their potential for craziness might have been realized-how their seeds might have sprouted little green shoots of weirdness, or even, with the right sort of anti-nurture, blossomed into full-blown lunacy. ${ }^{2}$ The assumption of the purity of nature is strikingly inverted.

Brian Bangs, instantly recognisable as the bachelor maths teacher, shows similar signs of delusion in his blindness to Bathsheba Hart's indifference to him: "Sheba likes me," he said quietly. "I know she does". 3 Barbara is perhaps similarly deluded about Miss Hart; however, more interesting still are the 'little green shoots of weirdness' that become more and more delectable sprouting through Sheba's peach-white skin. 
Eyre's characterisation of Barbara (Judi Dench) as 'The Crone' scraps the subtlety, the insight, and the vulnerability of Heller's original; moreover, the extent of Barbara's unreasonableness tends to simplify Sheba's (Cate Blanchett's) role. ${ }^{4}$ Stripped of all kindness, Eyre's Barbara is merely cruel and mad without a cause, unlike Sheba whose innocence shines the more starkly in contrast to Barbara's duplicity: 'What energy you spend on hating people!' Sheba observes. ${ }^{5}$ Eyre portrays Sheba as being only temporarily mad and with a cause, carefully excising from the film her incriminating sexual maternity, her obsessiveness, her retellings of retellings, and, most notably, her selfish need for Barbara as listener. The first paragraph of the foreword introduces this mutual dependency: 'I had heard most of it before, of course, there being few aspects of the Connolly business that Sheba has not described to me several times over'. ${ }^{6}$

In the film, Sheba takes Connolly's ultimate rejection of her placidly. This amicable end to the affair sees Eyre's film throw a more reasonable light on Sheba than does Heller's novel, which shows Sheba, after many unreturned calls, reluctantly confronting 'the possibility that she had been dumped'. 'Sheba returns to her husband and serves her prison sentence whereas Barbara survives to offend again. The cycle of the film closes on the bench where it opened-Barbara already luring in another unsuspecting female. ${ }^{8}$

In Heller's novel, most characters have the potential for madness because most can lose perspective given the right circumstances. It is not Barbara who becomes 'increasingly sinister"9 — her interest in Sheba's affair is clearly voyeuristic from the outset-rather, it is Sheba's experiences that characterise 'the right sort of anti-nurture' that blossom into 'full-blown lunacy'. Blanchett's concession to Connolly, 'You've done my brain in', ${ }^{10}$ tantalisingly hints at this lunacy, but Eyre unfortunately fails to develop it any further.

By the end, Heller's novel has affected a semi-chiasmus. Barbara is ultimately saner than Sheba, or at least less desperate: "What is going to become of me, Barbara?" she sobbed. "What is going to become of me?"' 11 Sheba is clinically depressed and, still stuck on Connolly, paralysed by her situation. Barbara's controlling behaviour-'How will Sheba manage on her own? Who will do the shopping and cook 
her meals? Who will make sure she showers every day?' ${ }^{12}$ - and her simultaneous indulgence of Sheba's retellings of the affair only reinforces Sheba's precarious mindset. Sheba's madness reverses the women's roles. Although Barbara is the author of Sheba's downfall, by sidestepping the depth of Sheba's fall, Eyre avoids any suggestion that the women are anything more than two-dimensional analogues. The darkest moment in the novel, however, is Barbara's discovery of Sheba's sculpture, notably absent from the film:

The cross-legged 'mother' figure had been fashioned in Sheba's image. She had long, skinny limbs, heavy, romantic eyelashes, a slightly crooked nose. Even her hair replicated Sheba's messy bun. As for the hideous, pink boy-man spilling fatly across her lap-he was a crude, but unmistakeable likeness of Connolly. ${ }^{13}$

Does Sheba really have any more excuse than Barbara for such an unbreakable obsession? Moreover, Heller's inclusion of such confused heterosexuality finely balances Barbara's suppressed lesbianism to neutralise the problem of simply heralding the latter as a dark, dangerous, and deluded sexuality — a trap Eyre's film fails to foresee. 


\section{Endnotes}

1. Richard Eyre cited, Zoë Heller, Notes on a Scandal (London: Penguin, 1997), p. i.

2. Zoë Heller, Notes on a Scandal (London: Penguin, 1997), p. 192.

3. Heller, p. 192.

4. Notes on a Scandal. Dir. Richard Eyre. Twentieth Century Fox. 2007.

5. Heller, p. 141.

6. Heller, p. 1.

7. Heller, p. 221.

8. 'Richard was right. He always said you were an incubus', Sheba snarls at Barbara in the penultimate chapter. Heller, p. 237.

9. Entertainment Weekly cited, Heller, p. ii.

10. Eyre, 2007.

11. Heller, p. 242.

12. Heller, p. 240.

13. Heller, p. 241. 